\title{
Operating Staff Optimization in Case of Headed Cabbages Mechanical Harvesting Under Adaptive Technologies
}

\author{
S. S. Alatyrev, A. S. Alatyrev, P.V. Misihin, \\ N. N. Pushkarenko \\ Department of transport-technological machines and \\ complexes; Department of technical service \\ Chuvash state agricultural Academy \\ Cheboksary, Russia \\ If7@academy21.ru \\ Yu.V. Loskutov \\ Center for basic education \\ Volga State University of Technology \\ Yoshkar-Ola, Russia \\ mikhail.loskutov@ro.ru
}

\author{
O. V. Mikhailova \\ Department of Industrial Automation \\ Volzhskiy branch of the Moscow Road Transport Institute \\ Cheboksary, Russia \\ stl_mstu@mail.ru
}

\author{
S.A. Ovchukova \\ Department of mechanization, electrification of automation of agricultural production \\ Chuvash state agricultural Academy \\ Cheboksary, Russia \\ Ovchukova1941@mail.ru
}

\begin{abstract}
A cabbage combine harvester adapted to technological schemes of harvesting is proposed: bulk shipment of heads in the vehicle bed and shipment of heads on flexible flooring with a subsequent delicate packing in containers in the vehicle bed. The machine harvesting process of headed cabbage under the schemes will be efficient and sustainable with optimal composition of the staff engaged in correcting of the non-marketable cut heads on the combine harvester and rearranging from flexible flooring to containers on the vehicle. To do this, the processes are modeled based on the theory of mass service of operations. Therein, correcting of the cabbage heads is considered as a multichannel queuing system (QS) with refusals, and the process of shipment and stacking of cabbages heads in containers - as a delay queuing system. We determined the optimal number of operating staff involved with the correcting of heads $n=2$ pers., and stacking of cabbages in containers $n=3$ people. The results of the calculations are checked and confirmed under production conditions.
\end{abstract}

Keywords- machine harvesting of cabbage, adaptive technological schemes, process modeling, queueing system, optimal composition of the personnel

\section{INTRODUCTION}

In Russia during reforms, the situation in vegeculture changed drastically [1]. In earlier times vegetable commodity production was dominated by large specialized farms with similar production conditions, but now commodity vegetables production, particularly head cabbage, is mainly done by individual entrepreneurs, farm households and farming enterprises [2]. Each of them has their specific production and agrotechnical conditions of cultivation and harvesting of cabbage. In addition, they have different financial means for harvesting process machinery. Therefore, nowadays creating an effective cabbage harvest technology, satisfying a query of several groups of consumers, is a hot topic.

\section{The ANAlysis Of Literature Data AND PROBlem STATEMENT}

As the analysis shows, at present, many countries pay close attention to the development of cabbage harvest technology [3, $4,5,6,7,8]$. The paper [9] reports on creation of a selfpropelled cabbage combine harvester, the reference [10] describes a patent for the cabbage harvest machine. The paper 
[11] describes the structure of the cabbage harvest machine design layout. However, the proposed cabbage harvest machines are univariant, therefore, cannot fully meet modern requirements.

In this regard, in our view, a new cabbage combine harvester is of practical interest (RF patents No.2329637, No.2365086, No.2527025, No.2310315, No.2554403), proposed in the Chuvash state agricultural Academy, adaptable to different production and agronomic conditions, thereby satisfying the requests of these groups of vegetables producers.

The combine harvester is mainly for harvesting headed cabbage under two adaptive technological schemes:

- bulk shipment of heads in the bed of the accompanying all-purpose vehicle;

- bulk shipment of heads in the vehicle bed and shipment of heads on a flexible flooring with a subsequent delicate packing in containers in the all-purpose vehicle bed.

A cabbage combine harvester includes a base unit with a cutterbar 1 and a correction table 2 made in the form of the conveyor-cutter, a loading unit 3 in the form of a raddle chain with the device 4 for heads shipment sparingly (Fig.1).

When a combine harvester operates under the first scheme, harvesting unit moves along the rows of cabbage (see Fig.1). The cutterbar 1 aligns heads in a row, separates them from the stumps. Next, a pile of cabbage, consisting of heads and cabbage leaves enters on the narrow side-mounted belt conveyor. During transportation, a part of loose leaves are eliminated on it through the edges of the conveyor army duck, and the other part of them is separated from the flow of heads by rollers leaves separating unit at the outlet of the cutting unit before entering on the correcting table 2 .

After entering on the correcting table, the cabbage heads are inspected. The staff selects a head with long stumps (they usually have rosette leaves), inserts them with the stump in the support openings of the conveyor-cutter, where they subsequently re-cropped by an undriven knife. Along with a stump rosette, leaves are also cut and separated from the head. Cut cabbage stumps roll down the tray on the ground, and the heads and the newly formed loose leaves come on the raddle chain 3 .

While transition from the correcting table to the elevator and on raddle chain loose leaves, small (immature) heads are eliminated, and the commodity cabbage heads come in a special device [12], which allows one to ship them into the body of the vehicle sparingly.

During combine harvester operation under the second scheme (Fig.2) unlike the previous, first heads are carefully shipped in a u-shaped flexible flooring, mounted over the containers in the body of the vehicle. Then the staff that is in the body between the rows of containers gently shift heads from the flooring into the containers 2 .
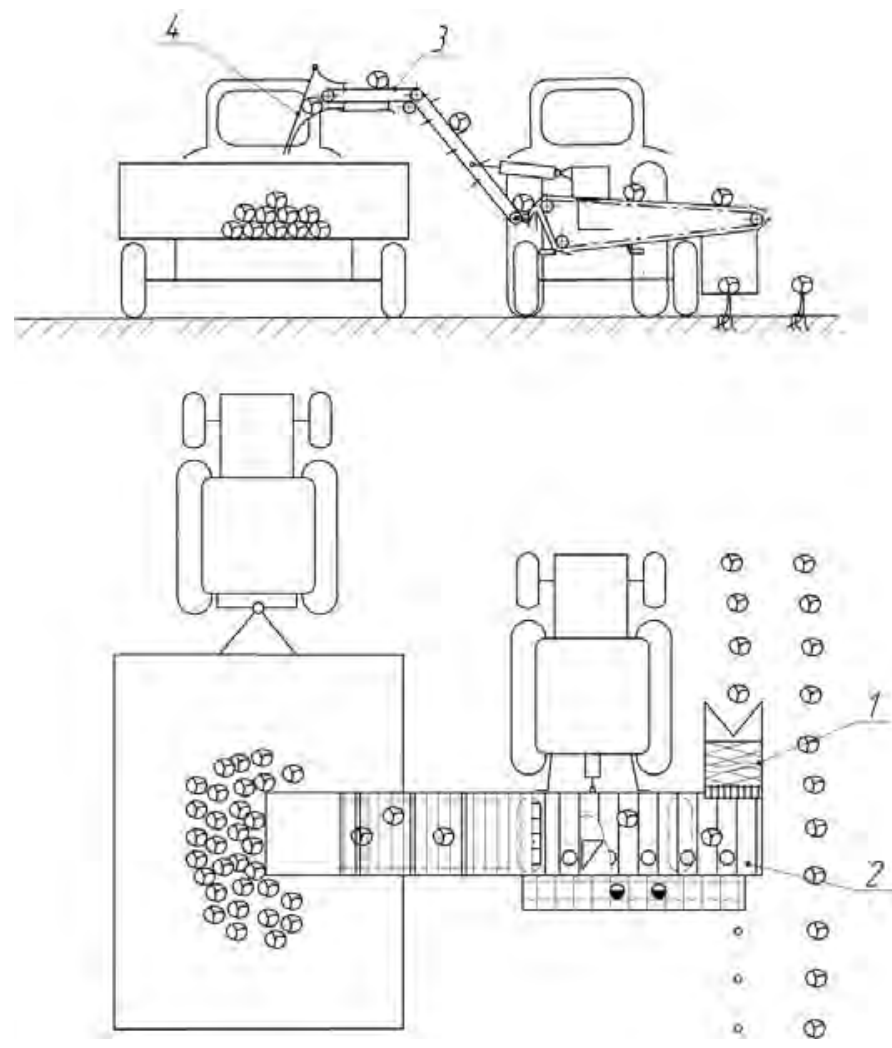

Fig. 1. Cabbage harvesting with a combine harvester under the scheme of bulk shipment of heads in the bed of the all-purpose vehicle

After filling the containers with cabbage heads, the vehicle goes into the storage area, where a forklift replaces full containers with empty, leaving flexible flooring 1 with a rack on the vehicle platform to perform a subsequent operation cycle. Further, the vehicle with empty containers and flooring 1 goes to the field to accompany the cabbage combine harvester.

Left containers with cabbage heads are stack in the storage area with a forklift.

The machine harvesting process of headed cabbage under the above-mentioned technological schemes will proceed efficiently and sustainably, if the operating staff on the combine harvester at the correcting table is able to identify non-tradable cut heads of cabbage in the support openings of the conveyorcutter, and the staff in the body of the vehicle timely shifts heads, coming to the flooring, to containers.

Otherwise, non-tradable cut heads, without waiting for the correction, will enter on the elevator, then to the delivery and there is no room on the flooring for entering heads, hence it is necessary to periodically stop the harvesting machine for a pause to free up room on the flooring for entering heads.

Let us note that the service process intensity of the above jobs increases with the number of staff. However, their number must be minimal to reduce labor cost to execute harvesting process, in other words it is necessary to establish a rational composition of staff. 


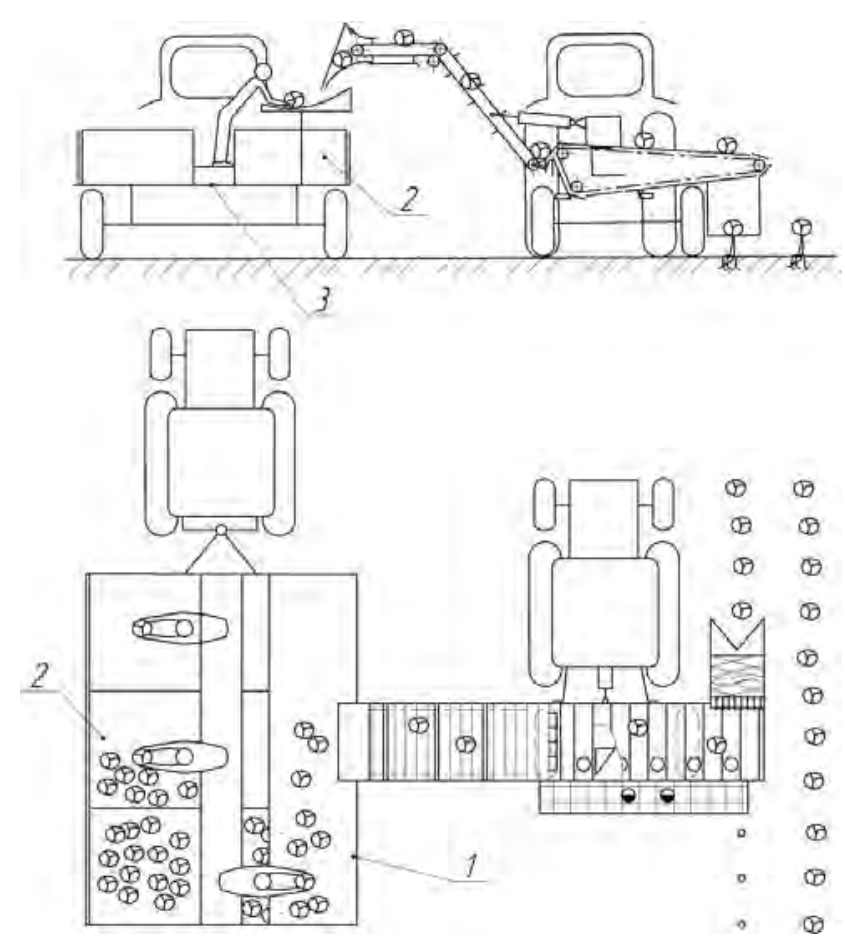

Fig. 2. Cabbage harvesting with a combine harvester under the scheme of bulk shipment of heads in the vehicle bed and shipment of heads on flexible flooring with a subsequent delicate packing in containers in the all-purpose vehicle bed.

\section{The Purpose AND OBJectives Of RESEARCH}

For the foregoing reasons, the purpose of the study is to optimize the operating staff composition in case of machine harvest of headed cabbages under adaptive technological schemes. tasks:

To achieve this goal, it is necessary to solve the following

- to model the process of cabbage heads product processing in a combine harvester;

- to model the process of heads shipment and stacking in containers on the vehicle;

- to establish quantitative relationship between performance indicators of the processes flow depending on the number of staff at these workplaces.

\section{METHODS AND RESULTS OF RESEARCH}

Optimization of the operating staff, in our opinion, can be successfully made on the basis of the theory of operations research [13]. Thus, the flow of the heads to the conveyorcutter, their inspection process, placing of non-tradable cut heads of cabbage in the support openings of the conveyorcutter, flow of the heads to a flexible flooring, the transfer process by the staff from the flooring in containers can be considered as tasks within the queue system (QS) of operations. Models of such QS are shown in Fig.3.
Next, let us research the models of QS harvesting of white cabbage first under the schema "a", and then under the scheme "b". To do this, let us divide the flow of cabbages coming from the cutting device to the conveyor-cutter to tradable and nontradable. Let us call non-tradable cut heads of cabbage as requests inflow (RI). We refer those inspecting the flow (setting the heads in the supporting openings of the conveyor-cutter) to the QS channels. Fig. 3 shows QS channels by positions from 1 to $\mathrm{n}$.

The QS is a multi-system with refusals, as when all the inspectors (system channels) are busy, a part of non-tradable cut heads of cabbage leaves the correcting table non-tradable, avoiding correction.

The overall intensity of the heads arriving on the correcting table when cabbage harvesting with a single row combine harvester can be determined based on the average operating speed $\vartheta_{c p}$ of the harvesting unit and the distance $a$ between cabbage plants in a row (plant spacing) using a formula:

$$
\lambda=\frac{v_{\text {mean }}}{a} .
$$

In this case, taking the percentage of non-tradable cut heads of cabbage in the total mass equal to $25 \%$, let us find the intensity of the RI:

$$
\lambda^{\prime}=\frac{\vartheta_{\text {mean }} \cdot 25}{a \cdot 100}=0.25 \frac{\vartheta_{\text {mean }}}{a} .
$$

When $\vartheta_{\text {mean }}=0.65 \mathrm{~m} / \mathrm{sec}, \quad a=0.6 \mathrm{~m}$ the RI intensity $\lambda=1.08 \sec ^{-1} \theta, \lambda^{\prime} \approx 0,3 \sec ^{-1}$.

The intensity of service by one channel can be determined experimentally on the basis of the service time $t_{\text {об }}$ of one head using a formula [14]:

$$
\mu=\frac{1}{t_{o b}} .
$$

When $t_{o b}=3 \ldots 4 c$, intensity of service is $\mu \approx 0,25 \ldots 0,33 c^{-1}$.

In the present QS, different states are possible. Let us designate the system possible states based on the number of simultaneously busy channels:

$S_{0}$ - all channels are free;

$S_{1}$ - one channel is busy, the others are free;

$S_{k}-k$ channels are busy, the rest are free;

$S_{k+1}-k+1$ channels are busy, the rest are free;

$S_{n}$ - all the $n$ channels are busy. 


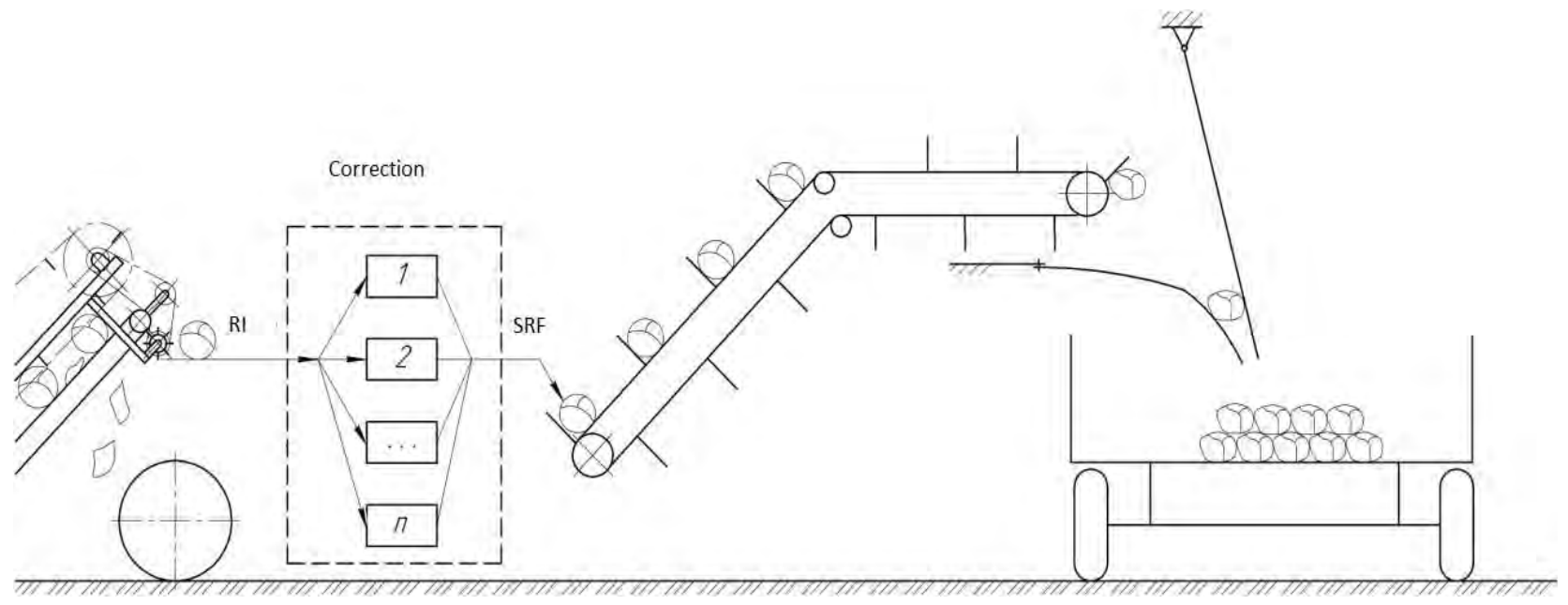

a)

Correction Packing

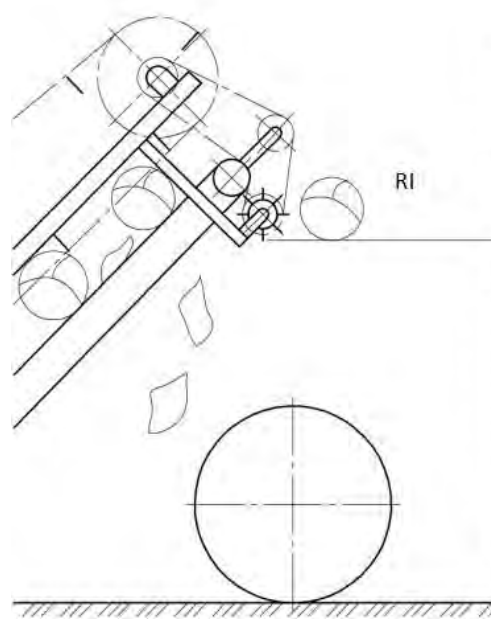

b)

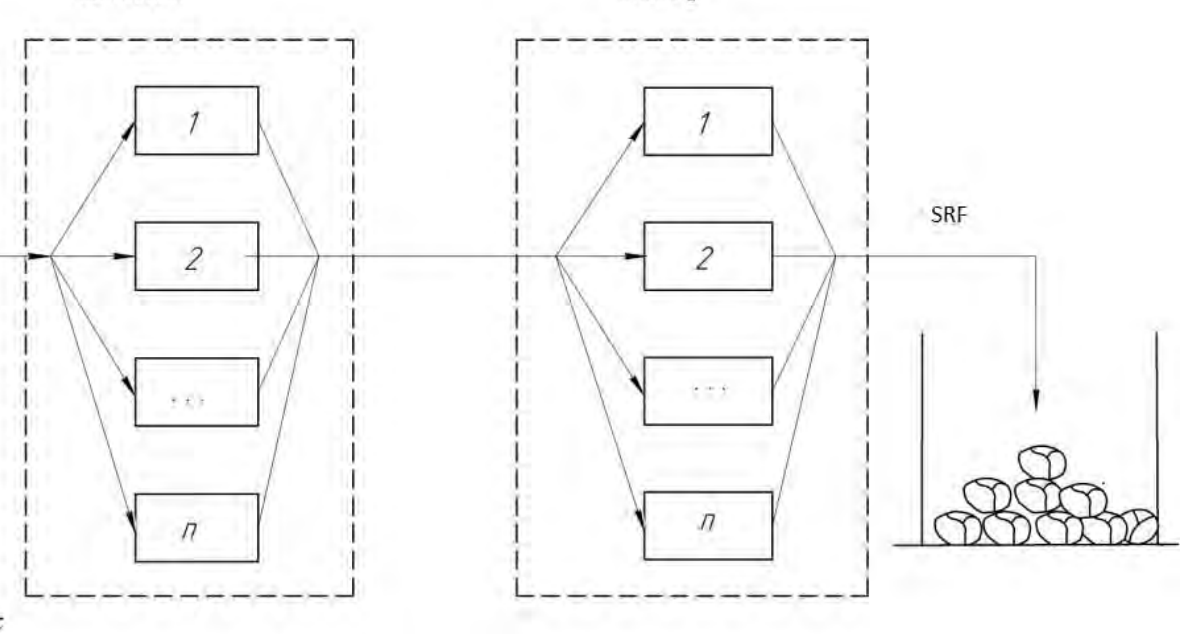

Fig. 3. QS models of cabbage harvesting with combine harvester of Chuvash state agricultural Academy design under schemes: a - bulk shipment of heads in the vehicle bed; $\mathrm{b}$ - shipment of heads on a flexible flooring with a subsequent delicate packing in containers; RI - requests inflow; SRF - serviced requests flow; 1, 2, ... $\mathrm{n}-\mathrm{QS}$ channels

The graph of the above states is given in Fig. 4. Here a corresponding event flow intensity is shown for each arrow. Let us note that from left to right along the arrows, the system is transferred from one state to another with the same requests intensity $\lambda^{\prime}$; from right to left along the arrows, the system is transferred from one state to another by the services stream, which intensity is $\mu$, multiplied by the number of busy channels. For example, let us suppose that the system is in the state $S_{0}$. From $S_{0}$ to $S_{1}$, the system is transferred by the flow with intensity $\lambda^{\prime}$ (when request comes, the system jumps from $S_{0}$ to $S_{1}$ ). Further, let us suppose that the system is in state $S_{1}$ (one channel runs). It produces $\mu$ services per unit of time and is free, i.e. the system enters the state $S_{0}$ again, etc.

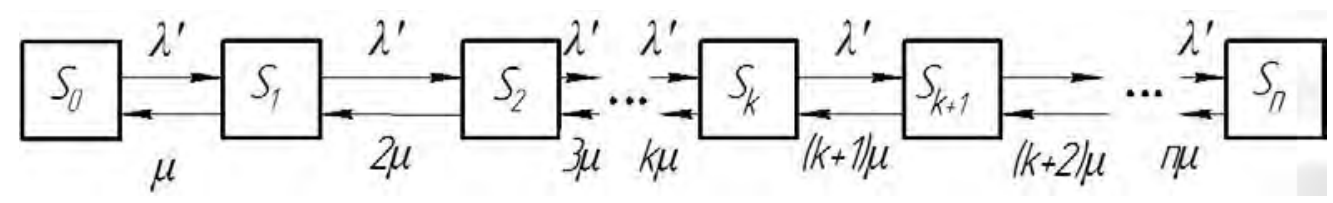

Fig. 4. QS state graph when correcting cabbage heads on the correcting table 
In this case, the limiting system state probabilities can be expressed using Erlang formulas [15]:

$$
\left.\begin{array}{l}
P_{0}=\left[1+\rho+\frac{\rho^{2}}{2 !}+\ldots+\frac{\rho^{n}}{n !}\right]^{-1} ; \\
P_{1}=\rho P_{0} ; \\
P_{2}=\frac{\rho^{2}}{2 !} P_{0} ; \\
P_{n}=\frac{\rho^{n}}{n !} P_{0},
\end{array}\right\}
$$

where $\rho=\frac{\lambda^{\prime}}{\mu}-$ the intensity of the channel load;

$P_{0}, P_{1}, P_{2}, \ldots, P_{n}$ - respectively limit system state probabilities $S_{0}, S_{1}, S_{2}, \ldots, S_{n}$.

In QS the likelihood of request service refusal $P_{\text {otk }}$ is equal to the probability that all channels are busy, i.e. the system is in the state $S_{n}$. Thus,

$$
P_{o t k}=P_{n}=\frac{\rho^{n}}{n !} P_{0}
$$

In this case, some portion of non-tradable cut heads of cabbage leaves the correcting table without service.

QS relative throughput rate (probability of requests service), we find using a formula:

$$
Q=P_{o b c}=1-P_{o t k}=1-\frac{\rho^{n}}{n !} \cdot P_{0} .
$$

The share of serviced requests (the percentage of corrected non-tradable cut heads of cabbage) can be expressed as follows:

$$
Q^{\prime}=\left(1-\frac{\rho^{n}}{n !}\right) \cdot P_{0} \cdot 100 \%
$$

QS, shown in Fig.3,b in terms of cabbage heads correcting process, has no difference from QS, described above. Therefore we study this model only in terms of the cabbage heads shipment and stacking in containers. In this case, at the QS input, requests flow will have an intensity determined by the formula (1) as non-tradable cut heads of cabbage once corrected will be in the main flow again.

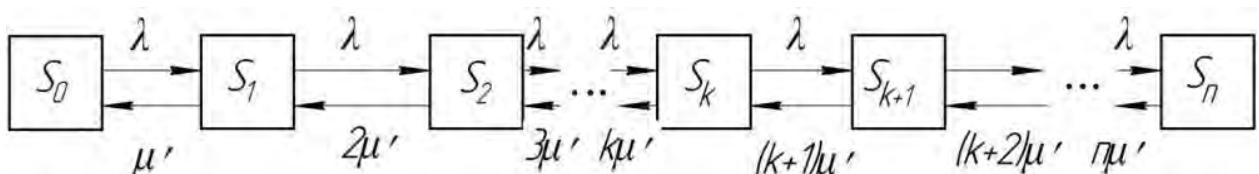

Fig. 5. QS state graph when shipment of cabbages on the flooring and their transfer in containers
Channel service intensity can also be determined experimentally on the basis of the service time of one head using a formula:

$$
\mu^{\prime}=\frac{1}{t_{o b}^{\prime}}
$$

where $t_{o b}^{\prime}=2.5$ and 2.8 with the service intensity $\mu^{\prime}$ $=0,33 \ldots 0.4 \mathrm{~s}^{-1}$.

The QS can be attributed to the multi-channel delay system, as the cabbage heads, not having the opportunity of service at the moment due to the fact that the channel is busy may temporarily remain on the flooring waiting for service.

In the present QS as in the previous case, different states are possible. Let us designate these possible states of the system also on the basis of the number of busy channels and the number of requests in the queue: $S_{0}$ - all channels are free; $S_{1}$ - one channel is busy, the others are free; $S_{k}-k$ channels are busy, the others are free; $S_{n}$ - all $n$ channels are busy $S_{n+1}$ - all $n$ channels are busy, one request is in the queue; $S_{n+r}$ - all $n$ channels are busy, $r$ requests are in the queue.

The state graph is shown in Fig. 5.

In this case, the expressions for the system states limit probabilities can be represented using a formula [15]

$$
\begin{aligned}
P_{0}^{\prime}=\left[1+\frac{\rho^{\prime}}{1 !}+\frac{\left(\rho^{\prime}\right)^{2}}{2 !}+\ldots+\frac{\left(\rho^{\prime}\right)^{n}}{n !}+\frac{\left(\rho^{\prime}\right)^{n+1}}{n !\left(n-\rho^{\prime}\right)}\right]^{-1} ; \\
P_{1}^{\prime}=\frac{\rho^{\prime}}{1 !} P_{0}^{\prime} ; \\
P_{2}^{\prime}=\frac{\left(\rho^{\prime}\right)^{2}}{2 !} P_{0}^{\prime} ; \\
P_{n}^{\prime}=\frac{\left(\rho^{\prime}\right)^{n}}{n !} P_{0}^{\prime} ; \\
P_{n+1}^{\prime}=\frac{\left(\rho^{\prime}\right)^{n+1}}{n n !} P_{0}^{\prime} ; \\
P_{n+2}^{\prime}=\frac{\left(\rho^{\prime}\right)^{n+2}}{n^{2} n !} P_{0}^{\prime} ; \\
P_{n+r}^{\prime}=\frac{\left(\rho^{\prime}\right)^{n+r}}{n^{r} n !} P_{0}^{\prime} .
\end{aligned}
$$

Here $\rho^{\prime}=\lambda / \mu \quad$ - the intensity of the channel load. 
Let us note, considering QS will operate in steady-state operating conditions when $\chi=\rho^{\prime} / n<1$. When $\chi \geq 1$, the queue of requests waiting for service will constantly increase. Therefore, hereafter we consider only options for which $\chi<1$. In QS in these options every request sooner or later will be served, so its characteristics will be respectively equal to:

probability of refusal $P_{r e f}=0$;

relative throughput of the system $q=1$;

absolute throughput:

$$
A=\lambda q=\lambda
$$

Therein the average number of requests waiting for service is determined using a formula [11]:

$$
\bar{r}=\frac{\left(\rho^{\prime}\right)^{n+1} P_{0}}{n \cdot n !(1-\chi)^{2}},
$$

and average waiting time of the request:

$$
t_{\text {og }}=\frac{\left(\rho^{\prime}\right)^{n} P_{0}}{n \dot{\mu} n !(1-\chi)^{2}} \text {. }
$$

An average number of busy channels is determined through an absolute throughput:

$$
\bar{z}=\frac{A}{\dot{\mu}}=\frac{\lambda}{\dot{\mu}}=\rho^{\prime},
$$

and probability of no queue in service when $n$ channels is using a formula:

$$
P_{o o}=P_{0}^{\prime}+P_{1}^{\prime}+P_{2}^{\prime}+\ldots+P_{n}^{\prime}
$$

\section{ANALYSIS AND DISCUSSION OF RESEARCH RESULTS}

The results of performance indicators, calculations of the QS, obtained using formulas (2) to (5) and (6) to (11) for a different number of channels $n$ are shown in tables 1 and 2 .

TABLE I. PERFORMANCE INDICATORS OF QS FUNCTIONING WHEN CORRECTING NON-TRADABLE CUT HEADS OF CABBAGE IN THE COMBINE HARVESTER

\begin{tabular}{|c|l|l|l|l|l|}
\hline $\mathbf{n}$ & \multicolumn{1}{|c|}{$\mathbf{2}$} & \multicolumn{1}{|c|}{$\mathbf{3}$} & \multicolumn{1}{|c|}{$\mathbf{4}$} & \multicolumn{1}{|c|}{$\mathbf{5}$} \\
\hline $\mathbf{P}_{\mathbf{0}}$ & 0.493 & 0.391 & 0.365 & 0.358 & 0.357 \\
\hline $\mathbf{P}_{\text {otk }}$ & 0.508 & 0.207 & 0.066 & 0.017 & 0.004 \\
\hline $\mathbf{Q}$ & 0.492 & 0.793 & 0.934 & 0.983 & 0.996 \\
\hline $\mathbf{Q}^{\prime} \mathbf{\%} \mathbf{0}$ & 49.2 & 79.3 & 93.4 & 98.3 & 99.6 \\
\hline
\end{tabular}

Table 1 shows that the above-mentioned was confirmed with the increased number of staff percentage of corrected heads is increased, therefore the total mass of the contents of non-tradable cut heads of cabbage is reduced.

According to the agro-technical requirements, one should strive for minimum content of non-tradable cut heads of cabbage, as the cabbages with long and cross cut stumps are a source of mechanical damage to adjacent heads. Besides, nontradable cut heads of cabbage, having covering leaves, impairs the process of heads ventilation in the layers of cabbage during storage.

Based on the calculations results, shown in table 1, it is possible to consider the optimal number of maintenance staff $n=2$, when the percentage of corrected heads among nontradable cut heads of cabbage is $79.3 \%$, which corresponds to $94.3 \%$ of the heads in the flow. The share of non-tradable cut heads of cabbage in the flow coming to be shipped is $5.7 \%$ only, which corresponds to the agro-technical requirements.

The adopted number of staff probability of failure in service of non-tradable cut heads of cabbage is 0.207 .

TABLE II. QS PERFORMANCE INDICATORS WHEN SHIPMENT OF CABBAGES ON THE FLOORING AND THEIR TRANSFER IN CONTAINERS $(\chi<1)$

\begin{tabular}{|c|c|c|c|c|c|c|}
\hline & \multicolumn{5}{|c|}{ QS indicators } & \\
\cline { 2 - 7 } $\begin{array}{c}\text { Number of } \\
\text { QS } \\
\text { channels } \\
\text { (number } \\
\text { of staff) n }\end{array}$ & $\boldsymbol{P}^{\prime} \boldsymbol{o}^{*}$ & $\boldsymbol{P}_{\text {oo }}$ & $\boldsymbol{A}$ & $\bar{r}$ & $\boldsymbol{T}_{\text {og, }} \boldsymbol{s}$ & $\bar{Z}$ \\
\hline $\mathbf{3}$ & $\begin{array}{l}0.01 \\
26\end{array}$ & 0.15 & 1.08 & 16.02 & 15.08 & 2.84 \\
\hline $\mathbf{4}$ & $\begin{array}{l}0.04 \\
75\end{array}$ & 0.64 & 1.08 & 1.087 & 1.01 & 2.84 \\
\hline $\mathbf{5}$ & $\begin{array}{l}0.05 \\
56\end{array}$ & 0.83 & 1.08 & 0.260 & 0.24 & 2.84 \\
\hline $\mathbf{6}$ & $\begin{array}{l}0.05 \\
77\end{array}$ & 0.90 & 1.08 & 0.07 & 0.07 & 2.84 \\
\hline
\end{tabular}

Table 2 shows that part of the heads $\bar{r}$ entered on a flexible flooring gets service refusal and waiting in the queue on the flooring, when the entire staff (all channels) are busy.

The number of those that are simultaneously on the flooring must not exceed the number of available place $[r]$ on it. Otherwise they will fall out of trough flooring; it is not permissible in conditions of the careful cabbage harvesting. Thus, when the working length of the tractor truck 2-PTS-4.5 $l=3900 \mathrm{~mm}$, the number of places available:

$$
[r]=7 \ldots 9 \text { places } \text {. }
$$

Thus, as table 2 shows, in order to satisfy the condition $r \leq[r]$, the number of personnel should be 4 people. Therein probability of no queue is 0.64 , the average number of requests waiting for service -1.087 , average waiting time of the request $-1.01 \mathrm{~s}$, the average number of busy channels -2.84 . 


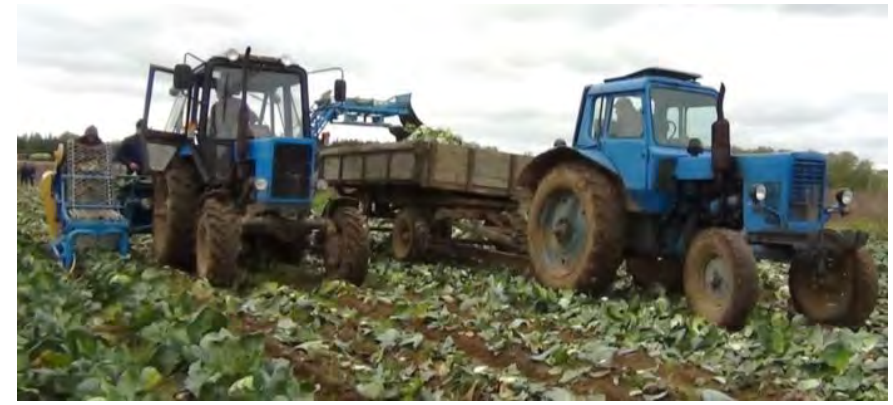

a)

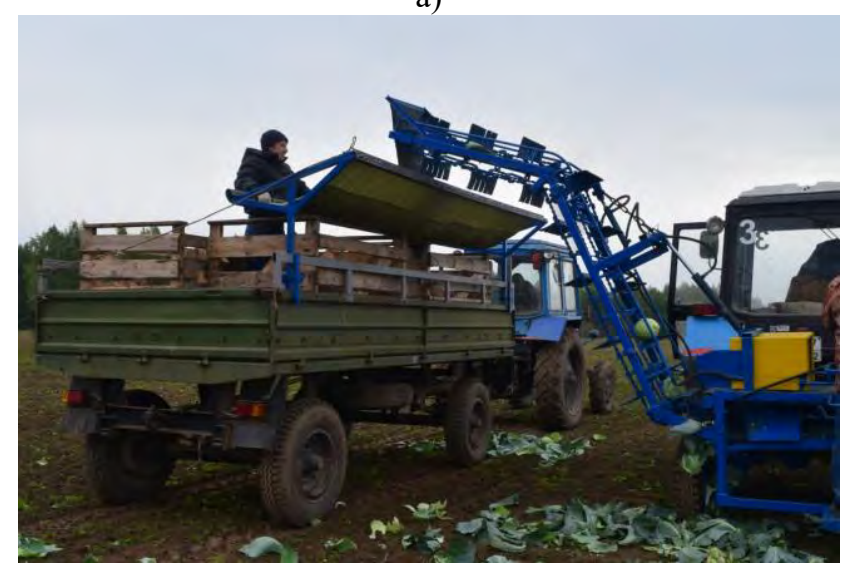

b)

Fig. 6. Production validation of the cabbage harvesting with the combine harvester of Chuvash state agricultural Academy design under the schemes: a bulk shipment of heads in the vehicle bed; b - shipment of heads on a flexible flooring with a subsequent delicate packing in containers in the vehicle bed.

However, it should be noted that the results of the calculations, shown in table 2 , are obtained when the intensity of the incoming flow is $\lambda=1.08 \mathrm{sec}^{-1}$ in relation to the theoretical cabbage plant $a=0.6 \mathrm{~m}$ spacing. However, often it turns out that part of the planted seedlings dies during the growing season; that is why the actual intensity of the incoming flow is usually less, $\lambda=1.08 \mathrm{sec}^{-1}$. In this regard the required number of staff can be reduced to 3 people.

The results of the cabbage mechanical harvesting process modeling according to the above schemes are tested under production conditions (Fig. 6). The number of staff was determined based on the results of the processes modeling of the cabbages handling and stacking in containers. When this harvest process was performed rhythmically without fail.

\section{CONCLUSION}

1) Cabbage combine harvesting process modeling is under two adaptive technological schemes:

- bulk shipment of heads in the bed of the accompanying all-purpose vehicle;

- bulk shipment of heads in the vehicle bed and shipment of heads on a flexible flooring with a subsequent delicate packing in containers in the all-purpose vehicle bed.
2) It is established that optimal numbers of staff, involved in the cabbage heads correcting and laying into the containers, that can be considered for these jobs, are respectively 2 and 3, when using the proposed combine harvester.

\section{Acknowledgment}

The research was done with the financial support from the Foundation for Assistance to Small Innovative Enterprises in Science and Technology in the framework of innovation project No. 2703ГC1/43156 "Development of a multivariate cabbage combine harvester and the technology of its use."

\section{References}

[1] S.S. Altarev, "On choosing of mechanized harvesting of cabbage in modern conditions", Machine technology and new agricultural machinery for Euro-North-East of Russia, pp. 130-137, June 2000 [materials of the 2nd International scientific-practical conference, p.165, 2000].

[2] S.S. Litvinov, "Vegetable growing of Russia and its scientific support", Potatoes and vegetables, vol. 10, pp. 2-4, October 2003.

[3] D.D. Du, J. Wang, S.S. Qiu, "Optimization of cutting position and mode for cabbage harvesting", Transactions of the CSAE, vol.30(12), pp.3440, 2014.

[4] D.Y. Geng, T.Z. Zhang, H. Luo, "Analysis of Agricultural Machinery Development Trend in Our Country", Transactions of Chinese Society for Agricultural Machinery, vol. 4, pp. 208-210, 2004

[5] M. Kanamitsu, K. Yamamoto, "Development of Chinese cabbage harvester", Japan Agricultural Research Quarterly (JARQ), vol. 30(1), pp. 35-41, 1996.

[6] N. Murakami, K. Otsuka, K. Inoue, "Robotic Cabbage Harveste", JSAM, vol.56(4), pp. 67-74, 1994.

[7] U.A. Gaede, Kohlerntemaschine E-804A hat die Prufung in der Praxis bestanden, vol.7 Gartenbau, 1985.

[8] Cabbage combine harvester Asa-lift [digital resource] /Access mode: http: www.m.autoline.com.ua free. The title screen.

[9] D.D. Du, G.Q. Fei, J. Wang, "Development and experiment of selfpropelled cabbage harvester", Chinese Society of Agricultural Engineering, vol. 31(14), pp. 16-23, 2015.

[10] C.J. Hansen, Harvesting machine for cabbage, or the like, United States Patent: 3827503, 1974.

[11] X.W. Wu, Y.J. Sun., X.K. Yuan, "Discussion on Structure of Selfpropelled Hydraulic Cabbage Harvester", South Agricultural Machinery, vol. 11, pp. 35-36, 1968.

[12] S.S. Alatyrev, I.S. Kruchinkina,A.P. Yurkin, A.S. Alatyrev, "Justification of shipment area of cabbages on a flexible flooring when machine harvesting", Bulletin of Krasnoyarsk state agrarian University,vol. 6(129), pp. 71-78, 2017.

[13] E.S. Wenzel, Operations research. Tasks, principles, methodology. Ed.2, 1988. 208 p.

[14] M.S. Guzanov, "Performance improvement of selective harvesting of early cabbage by improving technology and optimization of parameters of the harvest unit": Dis. ... Doctor of Science. - Saint-Petersburg, 2015. -156 p.

[15] E.S. Wenzel, Operations research. M., Soviet radio, 1972, 552 p. 